\title{
Polyaniline/MWCNT Nanocomposite as Sensor for Electroanalytical Determination of Phenol in Oil Field Wastewater
}

Fei Liu ${ }^{1, *}$, Shaocan Dong ${ }^{1}$, Zhaoxiang Zhang ${ }^{2}$, Xiaodong Dai ${ }^{1}$, Yanping Xin ${ }^{1}$, Xuewu Wang ${ }^{1}$, Kun Liu ${ }^{l}$, Zhenhe Yuan ${ }^{1}$, Jie Zhang ${ }^{1}$, Mengxin Chen ${ }^{1}$, Zheng Zheng ${ }^{1}$, Yingxue Xu ${ }^{1}$, Lin Xue

${ }^{1}$ Shengli College, China University of Petroleum, Dongying, Shandong, 257061, China;

${ }^{2}$ Shengli Oilfield Company Postdoctoral Research Station, SINOPEC, Dongying, Shandong, 257000, China;

*E-mail:

doi: $10.20965 / 2019.09 .79$

Received: 13 May 2019 / Accepted: 13 July 2019 / Published: 5 August 2019

The determination of phenol content in oilfield wastewater is very important in environmental control. In this paper, we present an in situ polyaniline-carbon nanotube (PANI/CNT) nanocomposite for the surface modification of a glassy carbon electrode. The modified sensor has a very sensitive electrochemical response to phenol and can linearly detect the phenol of $10 \mu \mathrm{M}$ to $0.5 \mathrm{mM}$ with a very low detection limit. Our proposed sensor has also been successfully used for phenol detection of actual samples of oilfield wastewater.

Keywords: Polyaniline; Carbon nanotubes; Electrochemical sensor, Phenol, Oilfield wastewater

\section{FULL TEXT}

(C) 2019 The Authors. Published by ESG (www.electrochemsci.org). This article is an open access article distributed under the terms and conditions of the Creative Commons Attribution license (http://creativecommons.org/licenses/by/4.0/). 